\title{
Sparkol Videoscribe Usage on Colloid Material as a Media for Chemistry Education
}

\author{
*Reny Septiani, Supriadi \& Ijirana \\ Pendidikan Kimia/FKIP - Universitas Tadulako, Palu - Indonesia 94119 \\ Received 19 December 2019, Revised 23 January 2019, Accepted 20 February 2020 \\ doi: 10.22487/j24775185.2020.v0.i1.pp47-52
}

\section{Abstract}

This research method was research and development ( $R$ \& $D$ ), which purposed to obtain the sparkol videoscribe designs of colloidal material and the validity of designs that were reviewed by experts as theoretical experts. The object of this study was sparkol videoscribe. Data collection was divided into two, namely media design data and media validity that were designed by using assessment sheets from 5 experts, 3 people were the learning media experts and 2 people were the chemical material experts. Data were analyzed descriptively to determine the justification of the validity of the research object. The results of the data analysis obtained that sparkol videoscribe design of material colloid had characteristics, namely images, moving hand animation, music, explanation of material in the form of sound and the composition of sentences incorporated in whiteboard animation. The designs were declared valid with a very good category according to experts and can be used as a chemistry education media with a score of 3.7 based on the total score of the instructional media experts and 3.45 based on the total score of the chemical material experts.

Keywords: Sparkol videoscribe, chemistry education media, learning media, colloid, research, and development

\section{Pendahuluan}

Perkembangan ilmu pengetahuan teknologi dan seni (IPTEKS) saat ini mengalami kemajuan dengan sangat pesat. Sejalan dengan kemajuan zaman dalam bidang ilmu IPTEKS, Perkembangan sains dan teknologi memiliki dampak positif dengan semakin terbuka dan tersebarnya informasi dan pengetahuan dari dan ke dunia melalui batas ruang dan waktu (Jamun, 2018). Dunia pendidikan selalu mengalami perkembangan dengan adanya pembaharuan-pembaharuan yang dilakukan mulai dari kurikulum, model pembelajaran dan media pembelajaran (Agustina, 2012).

Pendidikan seharusnya memainkan peran penting bagi perkembangan suatu bangsa. Beberapa negara dapat maju karena pendidikan (Alam, 2009). Pembelajaran tidak hanya menggunakan papan tulis saja dan pengajar tidak hanya berceramah di depan kelas sambil menulis di papan tulis, sementara peserta didik duduk, mendengar, dan mencatatnya. Berbagai media hasil teknologi termasuk di dalamnya televisi, VCD, DVD, dan komputer menjadi suatu kebutuhan penting dalam pembelajaran (Munir, 2010). Media pembelajaran digunakan untuk membantu memvisualkan bahan ajar yang bersifat abstrak dan juga membuat proses pembelajaran lebih menarik (Sari, 2014). Temuan Swan (1993) memberikan bukti bahwa penggunaan komputer dapat mengubah sifat pengajaran dan pembelajaran pada tingkat yang paling dasar tingkat interaksi antara siswa dan guru, penelitiannya menunjukkan interaksi siswa-guru lebih berpusat pada siswa dan individual selama pengajaran dan pembelajaran berbasis komputer daripada selama pengajaran dan pembelajaran tradisional. Penelitian Englund (2016) juga menunjukkan bahwa konsep pendekatan guru untuk mengajar dengan teknologi sangat penting bagi keberhasilan penerapan teknologi pendidikan.

Media pembelajaran diharapkan dapat menimbulkan kegiatan pembelajaran yang menarik, menyenangkan tetapi tetap mempunyai unsur keseriusan dalam belajar sehingga dapat melatih kemampuan memecahkan masalah. Faktanya 72,5\% siswa kelas XI dari SMA 17 Agustus 1945 Surabaya berdasarkan hasil angket mengaku tertarik jika pembelajaran kimia dilakukan dengan menggunakan media pembelajaran yang menyenangkan (Agustina, 2012).

Media video yang digunakan harus menyesuaikan konteks pembelajaran di lapangan (Seidel, 2013). Hasil yang terindikasi dari kebiasaan siswa menggunakan video, menjadikan media video semakin berguna sebagai media pembelajaran yang mudah digunakan (Kay, 2012). Kelebihan media video dibuktikan oleh Harwood (1998) bahwa siswa mendapatkan skor lebih tinggi secara signifikan dibandingkan dengan siswa yang tidak menggunakan video dalam proses pembelajaran.

*Correspondence:

Reny Septiani

e-mail: reni@seangle.org

(c) 2020 the Author(s) retain the copyright of this article. This article is published under the terms of the Creative Commons Attribution License 4.0, which permits unrestricted non-commercial use, distribution, and reproduction in any medium, provided the original work is properly cited. 
Hasil ini menunjukkan bahwa intervensi kurikulum media video terintegrasi dapat secara positif mempengaruhi prestasi dan sikap siswa serta video interaktif memungkinkan studi terperinci laboratorium atau peristiwa kehidupan nyata yang menarik dan dianggap sebagai teknologi penting dalam bidang pembelajaran berbasis komputer dalam sains (Weller, 1996) Mengacu pada fungsi media video sehingga membuat inovasi baru pada dunia pendidikan. Salah satunya adalah merancang media edukasi melalui video dengan sparkol videoscribe. Sparkol videoscribe merupakan software yang didesain untuk menghasilkan animasi papan tulis dan konsep teori yang kompleks dalam klip video pendek. Gambar dari sparkol videoscribe digunakan untuk meningkatkan video, kombinasi visual tangan, suara rekaman dan perolehan musik yang ringan dan menarik perhatian peserta didik saat mereka terlibat dalam pembelajaran. sehingga lebih menyenangkan untuk mempelajari pelajaran (Roy, 2017). Fitur yang disediakan oleh software ini sangat beragam sehingga mampu menjadi media pembelajaran yang dapat disesuaikan dengan mata pelajaran yang diinginkan.

Fakta tentang penggunaan sparkol videoscribe layak digunakan sebagai media pembelajaran sudah dilakukan oleh Wulandari (2016) melalui penelitiannya tentang pengembangan media pembelajaran menggunakan sparkol videoscribe pada mata pelajaran IPA di SMP bahwa hasil validasi dari mutu teknis sebesar $72.5 \%$ yang masuk dalam kategori baik, dan nilai aspek media sebesar $75.9 \%$ yang masuk dalam kategori baik. Sayangnya, pengembangan software sparkol videoscribe dalam media pembelajaran pada bidang kimia masih sangat jarang dilakukan. Materi Koloid dipilih karena materinya yang sangat dekat dalam kehidupan sehari-hari sehingga dapat divisualisasikan dalam bentuk video. Menurut isi Standar Kompetensi BSNP dalam materi Koloid dijelaskan sifat sistem koloid dan aplikasinya dalam kehidupan sehari-hari (Rahmawati, 2012). Adanya multimedia pembelajaran interaktif yaitu sparkol videoscribe diharapkan penggambaran mengenai materi Koloid akan semakin jelas, serta contoh dan pemanfaatan mengenai sistem koloid lebih aplikatif dan siswa menjadi lebih tertarik dan paham.

Tulisan ini dimaksudkan untuk mendeskripsikan penggunaan sparkol videoscribe materi koloid sebagai media edukasi kimia yang ditinjau dari para ahli sebagai pakar teori.

\section{Metode}

\section{Studi Pendahuluan}

Studi pendahuluan adalah tahapan awal dalam perancangan produk dengan mengadakan studi penelaahan terhadap buku-buku, literaturliteratur, catatan-catatan dan laporan-laporan yang ada hubungannya dengan penelitian yang akan dilakukan.

\section{Tahap Desain}

\section{Perancangan}

Kegiatan ini merupakan proses sistematik dalam merancang konten video. Tahap perancangan ini terdiri dari pembuatan sketsa konsep isi (storyboard) yang akan mempermudah dalam proses pembuatan video menggunakan sparkol videoscribe, dengan mengumpulkan materimateri Koloid dalam garis-garis besar, standar kompetensi hingga indikator pembelajaran, selanjutnya mengunduh beberapa gambar pendukung materi Koloid, musik latar belakang, serta teks skrip untuk pengisi suara.

\section{Pembuatan Media Edukasi Kimia}

Tahap pembuatan ini berisi kegiatan realisasi rancangan produk. Dalam tahap perancangan, telah disusun kerangka konseptual produk, berupa media edukasi kimia. Pada tahap ini, kerangka yang masih konseptual tersebut direalisasikan menjadi suatu produk yang siap dibuat. Proses pembuatan media edukasi kimia menggunakan sparkol videoscribe ini terdiri dari 2 tahap, yaitu pra-produksi dan produksi. Uraian dijelaskan dalam Gambar 1.

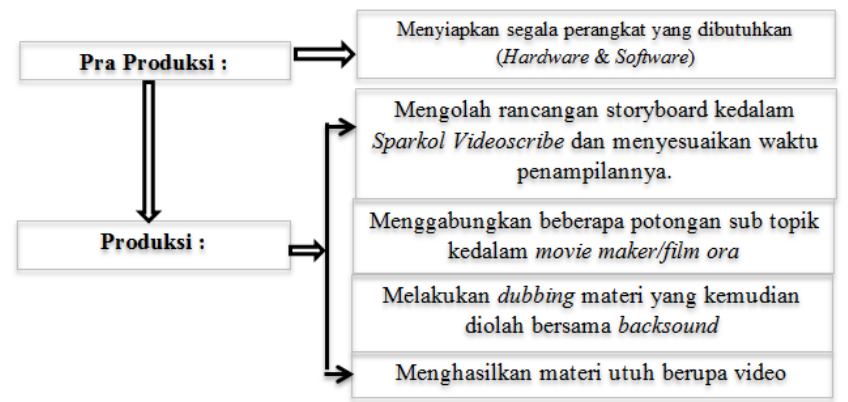

Gambar 1. Skema alur pembuatan media edukasi kimia

\section{Tahap Validasi}

Tahap validasi merupakan tahap berupa pengujian media edukasi kimia yang telah dirancang menggunakan sparkol videoscribe. Media yang telah selesai dirancang selanjutnya dinilai dan divalidasi oleh 3 orang ahli media pembelajaran dan 2 orang ahli materi kimia. Para ahli memberikan penilaian terhadap media edukasi kimia yang didesain. Hasil tersebut dianalisis kembali untuk mengetahui validitas media edukasi tersebut. 


\section{Teknik Pengumpulan Data}

Data yang dikumpulkan dalam penelitian ini digunakan sebagai bahan acuan guna menentukan validitas media edukasi melalui video berbasis sparkol videoscribe yang dirancang. Adapun teknik pengumpulan data yang diterapkan pada penelitian ini adalah lembar penilaian. Jenis lembar penilaian berupa angket tertutup dengan jenis skala Likert. Angket tertutup memiliki jawaban yang sudah disediakan dan tidak memberi peluang kepada responden untuk menambah keterangan lain (Maria, 2010). Adapun para ahli media pembelajaran dan materi kimia akan memberikan saran perbaikan pada kolom yang disediakan untuk mendukung perbaikan rancangan produk yang di buat.

\section{Teknis Analisis Data}

Pengujian validitas produk dilakukan dengan menggunakan skala Likert (Croasmun. 2011). Penentuan kategori nilai rata-rata indikator penilaian berdasarkan skala Likert dan menentukan nilai validitas setiap indikator penilaian ditunjukkan pada Tabel 1.

Tabel 1. Kategori validitas

\begin{tabular}{lll}
\hline No & Kategori & Skor \\
\hline 1 & Sangat Setuju & 4 \\
2 & Setuju & 3 \\
3 & Tidak Setuju & 2 \\
4 & Sangat Tidak Setuju & 1 \\
\hline
\end{tabular}

Keterangan:

$\mathrm{S}=$ Skor rata-rata yang diperoleh

Media edukasi kimia melalui video berbasis sparkol videoscribe dikatakan valid apabila semua indikator penilaian tersebut berada pada kategori Tinggi dan Sangat Tinggi (ST/T) (Mariyo, 2017).

\section{Hasil dan Pembahasan}

Sumber referensi untuk penelitian ini didapat dari sumber-sumber yang relevan yaitu: buku metode penelitian \& pengembangan oleh prof. dr. sugiyono, jurnal pendidikan desain \& validasi perangkat eksperimen induksi elektromagnetik alternatif sebagai media pembelajaran fisika SMA oleh rio hermadi, jurnal pembuatan bahan ajar fisika berbasis video menggunakan sparkol videoscribe untuk pembelajaran fisika siswa kelas XSMA oleh siti Fajar Aldilha Yudha dan buku ajar kimia kelas XI SMA.

Tahap desain dimulai dengan merancang alur konten video yang akan dibuat, hal ini untuk mempermudah peneliti dalam melakukan proses pengembangan selanjutnya. Alur konten video berisi alur materi koloid dan juga teks skrip untuk suara latar belakang serta gambar atau icon yang akan disisipkan dalam video dalam bentuk sketsa storyboard. Gambar yang digunakan untuk media edukasi ini yaitu gambar yang di unduh secara gratis melalui laman internet (http://bit.ly/kontengambar).

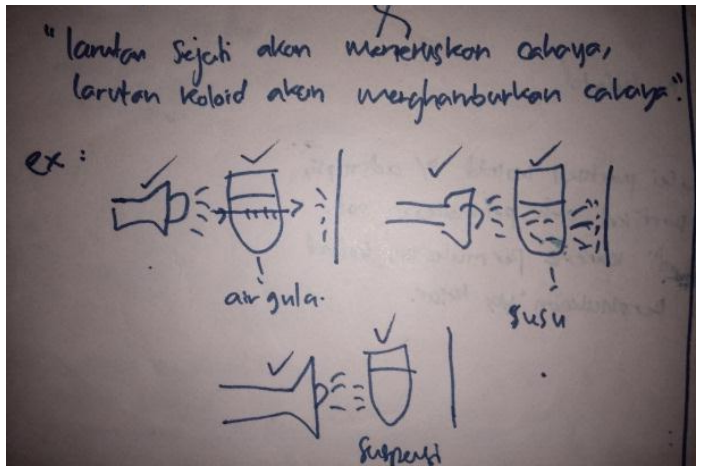

Gambar 2. Contoh sketsa storyboard

Tahap selanjutnya adalah tahap pembuatan, berisi kegiatan realisasi rancangan produk. Dalam tahap perancangan, telah disusun kerangka konseptual produk atau storyboard, yang kemudian dibuat menjadi media edukasi kimia berupa video menggunakan sparkol videoscribe. Proses produksi media edukasi kimia menggunakan sparkol videoscribe ini terdiri dari dua tahap yaitu pra produksi dan produksi.

Tahap pra produksi dimulai dengan menyiapkan segala perangkat yang dibutuhkan untuk membuat media pembelajaran, baik perangkat keras maupun perangkat lunak. Perangkat keras terdiri dari laptop, pengeras suara, sedangkan perangkat lunak terdiri dari software utama dari pembuatan media ini yaitu sparkol videoscribe, selain itu disiapkan juga software pendukung agar media dapat dikemas sesuai kebutuhan yaitu film ora sebagai aplikasi untuk menyatukan potongan-potongan video yang telah dibuat. film ora juga digunakan untuk menyisipkan 
suara latar belakang dan juga suara pengiring agar video yang dihasilkan lebih menarik.

Tahap produksi dimulai dari pembagian materi menjadi 8 sub topik, karena media edukasi akan dibuat menjadi beberapa potongan video. $\mathrm{Hal}$ ini agar dalam proses produksi media edukasi dari software sparkol videoscribe tidak membutuhkan waktu yang lama. Langkah selanjutnya adalah mengolah materi koloid yang sebelumnya telah dirancang dengan memasukkan gambar yang sebelumnya telah di unduh ke dalam sparkol videoscribe, kemudian disesuaikan dengan waktu penampilannya. Selanjutnya adalah menyimpan hasil pengembangan video tersebut dan di export ke dalam mp4 agar dapat di akses menggunakan pemutar video. Video tersebut kemudian di import kembali kedalam aplikasi Filmora yang ada di ponsel pintar untuk kemudian di tambahkan beberapa musik pengiring dan rekaman suara untuk menjelaskan materi koloid di video. Filmora merupakan aplikasi untuk mengedit video, memangkas serta mengonversi segala jenis video (Punusingon, 2017). Filmora dipilih karena kualitas video yang dihasilkan tidak mengubah ukuran video dan juga jenis video yang dihasilkan adalah high definition (HD). Setelah beberapa potongan video sudah selesai dikembangkan, melalui Filmora potongan-potongan video tersebut disatukan menjadi satu video yang berisi materi koloid secara keseluruhan.

\section{Validasi Media Edukasi}

Tahap terakhir penelitian ini adalah validasi media edukasi yang telah di desain menggunakan sparkol videoscribe. Validator terdiri dari 3 orang ahli media pembelajaran dan 2 orang ahli materi kimia. Media edukasi kimia harus di validasi oleh validator dan dilakukan revisi seperlunya oleh peneliti sesuai dengan saran dari 5 ahli tersebut, sehingga media pembelajaran yang dibuat dinyatakan valid dan dapat digunakan sebagai media pembelajaran. Penilaian oleh para ahli dilakukan dengan memberikan penilaian pada angket yang diberikan mulai dari tidak baik hingga sangat baik, serta memberikan komentar berupa saran perbaikan pada media pembelajaran yang divalidasi.

Ahli media pembelajaran dalam penelitian ini adalah dosen FKIP di Universitas Tadulako, programmer di UPT.TIK Universitas Tadulako, serta dosen FKIP di Universitas Negeri Surabaya. Adapun hasil validasi dari 3 orang ahli media pembelajaran terdapat dalam Tabel 2.

Tabel 2. Hasil penilaian ahli media pembelajaran

\begin{tabular}{llll}
\hline Aspek Penilaian & $\begin{array}{l}\text { Rata-rata per } \\
\text { Aspek }\end{array}$ & Kategori & $\begin{array}{l}\text { Justifikasi } \\
\text { Validitas }\end{array}$ \\
\hline Mutu Teknis & 3.62 & Sangat Tinggi & Valid \\
Aspek Media & 3.69 & Sangat Tinggi & Valid \\
Jumlah & 3.65 & Sangat Tinggi & Valid \\
\hline
\end{tabular}

Saran perbaikan dari 3 orang ahli media pembelajaran berupa media yang dikembangkan sudah cukup baik, namun harus ada penjelasan tentang perbedaan dengan media yang dikembangkan oleh peneliti sebelumnya, setiap pergantian sub materi atau materi, perlu jeda waktu beberapa detik, sebagai produk skripsi, harus ada identitas program studi, jurusan, pembimbing dan mahasiswa dan pada akhir video diakhir dengan ucapan terima kasih. Saran perbaikan dari ahli media pembelajaran yang diberikan sudah dilakukan dan diperbaiki.

Validitas materi pada rancangan media pembelajaran ini dilakukan oleh 2 orang ahli materi, yaitu dosen kimia di FKIP Universitas Tadulako dan guru kimia di SMA Negeri 3 Palu.. Adapun hasil penilaian dari ahli materi kimia dapat dilihat dalam Tabel 3.

Tabel 3. Hasil penilaian ahli materi kimia

\begin{tabular}{|c|c|c|c|}
\hline $\begin{array}{l}\text { Aspek } \\
\text { Penilaian }\end{array}$ & $\begin{array}{l}\text { Rata-rata per } \\
\text { Aspek }\end{array}$ & Kategori & $\begin{array}{l}\text { Justifikasi } \\
\text { Validitas }\end{array}$ \\
\hline Media & 3.5 & Sangat Tinggi & Valid \\
\hline Isi & 3.33 & Sangat Tinggi & Valid \\
\hline Jumlah & 3.4 & Sangat Tinggi & Valid \\
\hline
\end{tabular}

Saran perbaikan ahli materi kimia berupa secara sistematik video pembelajaran tersebut sudah memenuhi materi koloid. Akan tetapi, secara kurikulum penulisan standar kompetensi \& kompetensi dasar tidak sesuai dengan kurikulum $\mathrm{K} 13$, videonya cepat sehingga siswa agak sulit untuk memahaminya, audio terlalu cepat, materi perlu dikembangkan ke berfikir kritis, misalnya perbedaan larutan, koloid dan suspensi yang didasarkan oleh cahaya diteruskan dan dihamburkan. Perlu ada pertanyaan lanjut mengapa larutan sejati, cahaya diteruskan sedangkan koloid dan suspensi cahaya di hamburkan, audio perlu ada jedah, pertanyaan mengapa demikian, apa sebabnya lalu kemudian ditayangkan kembali. Dengan demikian, materi pada media pembelajaran yang dirancang ini yaitu materi Koloid dapat dipertanggung jawabkan kebenarannya. 
Pengembangan media edukasi kimia berbasis sparkol videoscribe dikemas dengan konten yang dapat memudahkan para penggunanya. Pemilihan teks yang disesuaikan dengan jenis dan ukuran yang jelas, pemilihan warna, gambar dan musik yang mampu menarik perhatian penonton atau siswa dalam belajar khususnya pelajaran kimia materi Koloid. Ketercapaian media edukasi kimia berbasis sparkol videoscribe ini dibuktikan melalui validasi oleh para ahli dengan hasil sebagai berikut, tiga ahli media pembelajaran melihat dari mutu teknis media edukasi kimia berbasis sparkol videoscribe yang terdiri dari 5 butir penilaian yaitu ukuran, warna dan jenis huruf yang digunakan, keterpaduan warna antar komponen (tulisan, gambar, grafis dan lainlain), gambar/animasi tidak mengganggu elemen lain yang berhubungan dengan materi, dan musik pengiring (backsound) yang digunakan memiliki volume yang proporsional dengan nilai rata-rata sebesar 3.62, dan melihat dari aspek media yang terdiri dari 13 butir penilaian yaitu tulisan, suara, animasi yang dimuat dalam media jelas, media yang digunakan menarik sehingga mampu menghibur dam merangsang pada siswa untuk belajar, media yang digunakan dapat dioperasikan dengan mudah, praktis, dapat dipelihara dengan mudah, dapat dijalankan dalam berbagai software dan hardware, dapat dikembangkan untuk pembelajaran lain serta media pembelajaran dapat digunakan kembali untuk belajar di rumah oleh siswa dengan memberikan nilai dengan rata-rata sebesar 3.69. Sedangkan dua orang ahli materi kimia melihat dari aspek media yang terdiri dari 8 butir penilaian yaitu penyajian gambar, audio, indikator sesuai dengan materi koloid, media yang disajikan masuk akal dan dapat diterima , sistematika penyajian materi koloid rapi, runtut dan jelas dan lengkap dengan nilai ratarata sebesar 3.50, dan melihat dari aspek kesesuaian materi yag terdiri dari 3 butir penilaian yaitu penggunaan bahasa indonesia yang baik dan benar, artikulasi bahasa jelas dan dapat dipahami serta materi koloid yang disajikan sesuai dengan silabus mata pelajaran kimia dengan nilai dengan rata-rata sebesar 3.33.

Berdasarkan penilaian yang diberikan para ahli, yaitu 3 ahli media pembelajaran dan 2 ahli materi kimia, maka rancangan media edukasi kimia ini memenuhi syarat visuals yaitu: Visible atau mudah dilihat dan dibaca, Interesting atau menarik untuk terdorong memperhatikan pesan melalui media tersebut, Useful atau bermafaat dalam hal pencapaian tujuan pembelajaran, Accurate atau benar sesuai dengan karakteristik materi, Legitimate atau sah dibuat untuk kepentingan pembelajaran oleh orang yang berwenang serta Structure atau terstruktur baik dalam pembuatan atau penggunaannya memperoleh skor penilaian 3,69 berdasarkan skor rata-rata dari 3 ahli media pembelajaran dan 3,50 berdasarkan skor rata-rata 2 ahli materi kimia dan masuk dalam kategori Sangat Tinggi dengan justifikasi validitas Valid. Sehingga media edukasi kimia berbasis sparkol videoscribe pada materi Koloid ini dapat dijadikan sebagai media pembelajaran dan dapat diteruskan ke tahap uji praktikalitas.

\section{Kesimpulan}

Desain sparkol videoscribe materi Koloid sebagai media edukasi kimia telah melalui beberapa tahapan pengembangan menggunakan metode research and development yaitu tahap studi pendahuluan, desain, serta dilakukan revisi untuk menghasilkan produk yang valid. Hasil data yang diperoleh bahwa sparkol videoscribe yang didesain memiliki karakteristik yaitu gambar, animasi tangan yang bergerak, musik, penjelasan materi berupa rekaman suara dan susunan kalimat yang disatukan dalam animasi papan tulis berwarna putih. Validitas sparkol videoscribe sebagai media edukasi kimia materi Koloid memperoleh skor rata-rata 3,65 berdasarkan ahli media pembelajaran dalam kategori sangat baik dan valid, dan untuk hasil validasi dari ahli materi kimia adalah sebesar 3.4 dalam kategori sangat baik dan valid.

\section{Ucapan Terima kasih}

Penulis mengucapkan terima kasih kepada seluruh pihak yang telah membantu penulis dalam menyelesaikan penelitian ini.

\section{Referensi}

Agustina, A., \& Novita, D. (2012). pengembangan media pembelajaran video untuk melatih kemampuan memecahkan masalah pada materi larutan asam basa. Jurnal Pendidikan Kimia Unesa, 1(1), 2252-9454.

Alam, G. M. (2009). The role of science and technology education at network age population for sustainable development of Bangladesh through human resource advancement. Academic Journal, 4(11), 1260-1270.

Croasmun, J. T., \& Ostrom, L. (2011). Using Likert-Type Scales in the Social Sciences. Journal of Adult Education, 40(1), 19-22.

Englund. C., Anders, D., Olofsson, \& Linda, P., (2016). Teaching with technology in higher education: understanding conceptual change and development in practice. Journal Higher Education Research \& Development, 36(1), 73-87.

Harwood, S. W., \& McMahon, M. M. (1998). Effects of integrated video media on student achievement and attitudes in high school chemistry. Journal of Research Science Teaching, 34(6), 617-631.

Jamun, Y. M. (2018). The impact of technology on education. Jurnal Pendidikan dan Kebudayaan Missio, 10(1), 48-52.

Kay, R., \& Kletskin, I. (2013). Evaluating the use of problem-based video podcasts to teach 
mathematics in higher education. Journal of Computers \& Education, 59(1), 619-627.

Maria, E. (2010). Hubungan penghargaan intrinsik terhadap motivasi kerja. Jurnal Bisnis dan Ekonomi, 17(1), 1-9.

Mariyo, H, Zulhelmi, Sudrajad, H. (2017). Rancang bangun dan validasi perangkat eksperimen fluida dinamis sebagai media pembelajaran fisika sma. Jurnal Online Fakultas Keguruan dan Ilmu Pendidikan Universitas Riau (JOM FKIP RIAU), 4(1), 110.

Punusingon, R. R., Lumenta, A. S. \& Rindengan, Y.D.Y. (2017). Animasi sosialisasi undangundang informasi dan transaksi elektronik. Jurnal Teknik Informatika Universitas Sam Ratulangi, 12(1), 1-8.

Rahmawati, D. (2012). Chemistry student worksheet with sets (science technology environment society) oriented to colloid topic for rsmabi. Unesa Journal of Chemical Education, 1(1), 62-69.

Roy, V. (2017). Digital storytelling for start-ups: a canadian mooc design experience. In proceedings of EMOOCs 2017: Work in Progress Papers of the Experience and Research Tracks and Position Papers of the Policy Track. (pp 34-39). Calgary Canada.

Sari, W. K., Saputro, S., \& Hastuti, B., (2014). Pengembangan game edukasi kimia berbasis role playing game (rpg) pada materi struktur atom sebagai media pembelajaran mandiri untuk siswa kelas $\mathrm{x}$ sma di kabupaten purworejo. Jurnal Pendidikan Kimia (JPK), 3(2), 96-104.

Seidel, T., Blomberg, G., \& Renki, A. (2013). Instructional strategies for using video in teacher education. Journal Teaching and Teacher Education, 34, 56-65.

Sugiyono. (2015). Metode penelitian dan pengembangan. Bandung: Alfabeta.

Swan, K., \& Mitrani, M. (1993). The changing nature of teaching and learning in computerbased classrooms. Journal of Research on Computing in Education, 26(1), 40-54.

Weller, H. (1996). Assessing the impact of computer based learning in science. Journal of Research on Computing in Education, 28(4), 461-485.

Wulandari, A. D. (2016). Pengembangan media pembelajaran menggunakan sparkol videoscribe dalam meningkatkan minat belajar siswa pada mata pelajaran ipa materi cahaya kelas viii di smp negeri 01 kerjo tahun ajaran 2015/2016. Skripsi Tidak Diterbitkan. Semarang: Universitas Negeri Semarang.

Yudha, S. F. A., Asrul, A., \& Kamus, Z. (2016). Pembuatan bahan ajar fisika berbasis video menggunakan sparkol videoscribe untuk pembelajaran fisika siswa kelas x SMA. Pillar of Physics Education, 8(1), 153-160. 